\title{
Be Creative!
}

\section{The In Be-Tween Trailer Team}

\author{
CAROL WAXMAN
}

I $\mathrm{n}$ applying for the Curiosity Creates grant, my colleague Jane Breen and I wanted to promote our new In Be-Tween Room, a space designed to showcase tween books as well as provide technology (including a Lenovo touch table and a Wii U gaming system) and encourage reading among that age group.

The In Be-Tween Trailer Team project was created to present students in grades four through six with an opportunity to work together with teen volunteers and use their imaginations to generate movie trailers and graphic posters of their favorite tween reads.

The program was offered four times during the grant period from January to May 2016, in four-week sessions; fifty students participated. The first week of each session was held at the Noah Webster Library (Main Library in West Hartford, Connecticut). The students chose a book to read from a selection "book talked" by children's librarians, and met the other students on their team and the teen volunteers.

Subsequent weeks were held at the West Hartford Community Access Station (WHC-TV) in West Hartford's Town Hall, a block away from the library. Each team created a book trailer, with the help of WHC-TV staff, as well as a book poster, assisted by a graphic artist from the West Hartford Public Schools.

The book trailers were posted to the West Hartford Public Libraries website and WHC-TV. The posters will be on display at the library, the Town Hall, local schools, and several other venues. A grand finale reunion was held at the library, where all team participants, their families, the teen volunteers, WHC-TV staff, and library staff were invited to view the book trailers and posters and share their Curiosity Creates experiences.

The program was promoted on the library website, in fliers at all three West Hartford library buildings, and in all eleven elementary and two middle school newsletters.

The objective proposed having each team of two students produce a book trailer and a graphic poster. In doing so, and in reading the books to produce the trailer and poster, the related goals of motivating the students to read and visit the library and the In Be-Tween Room, were also satisfied.

Jane and I, co-writers of the grant request, observed that students who had never met before the first program session (and chosen by us to be teammates) bonded instantly. They used their combined creativity to produce the trailers and posters. Many became fast friends, pooling their literary knowledge of the book with their tech and graphic experience to produce incredible works.

One of the more challenging teams-twin brothers who were quite active and needed a bit of reminding to stay on

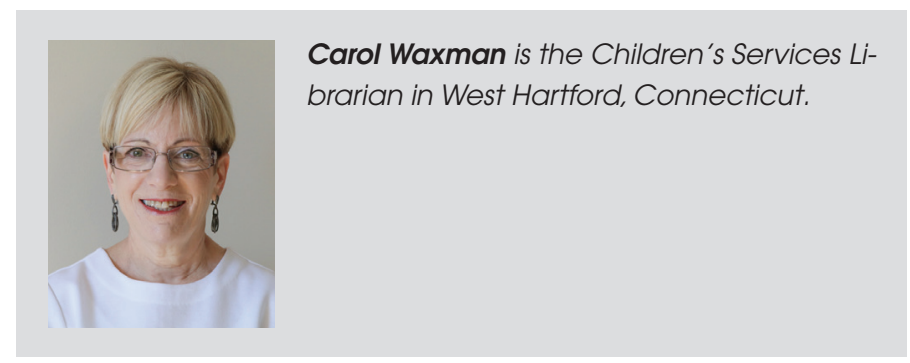


task-hugged me at the end of the Trailer Team session and told me they would miss me and miss being involved with the project.

We (librarians, TV station staff, school graphic artist) were astonished by the wide range of creative and critical thinking, original ideas, use of technology, and artistic talent demonstrated. Most were readers before they started the project, but none had produced a trailer or a poster prior to the grant start.

We gave the participants a pre-evaluation before they started the project to determine their reading habits, if they had previously visited a TV studio, used graphic software, etc. and conducted a post evaluation after the sessions with questions more specific to the project.

In a post-evaluation, these questions were answered and average response shown: ( 1 being the lowest rating and 5 the highest rating.)

\section{- Overall, how would you rate this workshop? 4.87}

\section{- Would you recommend the workshop to your friends? 4.75}

\section{- Do you think you will read more often now? 4.625}

- How likely are you to visit the In Be-Tween Room now? Twenty-one answered More Likely, seven answered Somewhat Likely, four answered Same and one answered Less Likely

Many parents commented that their children would never have had an opportunity to visit or work in a TV studio or use the equipment needed to produce the trailer without this grant opportunity. Many had never used even graphic software. Everyone appreciated being able to participate at no cost to the family and found the chance for their children to partake in a library program specifically designed for their age group, invaluable.

Seeing the excitement and energy in the Trailer Teams as they worked at the TV studio to create their trailers and posters was very satisfying. Developing new skills that involved technology is a great interest to most students this age, and it was evident that the teams reflected this. The equipment used to produce the trailers, especially the green screen, was a thrill to all participants.

We librarians also learned how to create a trailer, what is involved in making a poster using graphic software, and so much more. We used this experience to enrich our library tour of all eleven elementary schools in West Hartford in May 2016.

We visited the children in grades K-5 in preparation for our summer reading program and regaled them with several book trailers! We hope this encouraged them to check out books this past summer to fulfill their summer reading assignments.

The grant funding was $\$ 7,500$, of which we used all but $\$ 6$. We were able to purchase $\$ 3,500$ in tween-appropriate hardcover books, and the remainder of the grant funding paid for graphic software, supplies, and substitute staff in the library (while the librarians were working with the grant participants), as well as the technicians in the TV studio.

It would be wonderful if all libraries could replicate this program. A neighboring TV studio would be helpful to film the trailers and introduce TV studio technologies to the students. If the technicians require payment for their time, the additional funds would fulfill this requirement.

It was a great incentive, too, to receive monies to purchase additional books for our In Be-Tween Room, but this would not be a requirement. If you plan to produce posters, you will also need $\$ 400$ to $\$ 500$ to purchase graphics software.

As authors of the grant, we were delighted and surprised by the creativity demonstrated by the participants. Their ideas and suggestions were intuitive, original, and mature. We observed that they were constantly thinking and were confident enough to express their ideas in front of the group. We were thrilled that the tangible results of this project, posters and trailers, fulfilled the objective of the grant-be creative. The students will have these items to keep for a lifetime.

As facilitators of the grant, we were also gratified to discover that the students bonded immediately upon being assigned to a team of two. Most partners did not know each other prior to their participation in this project. In fact, many attended different schools. Happily though, all teams started to work together immediately, creating their storyboards, deciding on graphics, choosing props, and filming their trailer.

We are grateful to the Association for Library Service to Children and Disney for providing us with the opportunity to create and offer this project for the children in our community. We hope that other communities can replicate this program, using ours as a model.

For photos, images of the posters and the book trailers, please visit http://66.39.72.90/children/trailerteam. ¿ 